\title{
CENAS DE UMA ATIVIDADE DE LEITURA EM UM CONTEXTO DE ENSINO-APRENDIZAGEM DE PORTUGUÊS COMO LÍNGUA DE HERANÇA: APONTAMENTOS INTERCULTURAIS 1
}

\author{
Fernanda de Castro Modl \\ Nádia Dolores Fernandes Biavati ${ }^{* *}$ \\ Eulália Leurquin ${ }^{* * *}$
}

RESUMO: Neste artigo, apresentamos duas cenas de uma aula de português como língua de herança na Alemanha e demonstramos como os conceitos de cultura(s) como uma programação coletiva da mente (Woodside, 2010) e território(s) são úteis para entendermos como uma professora brasileira é surpreendida pelo modo como os seus alunos germânico-brasileiros, nascidos e criados na Alemanha, interpretam o texto-objeto de Ensino (uma propaganda verbo-visual impressa). Os apontamentos interculturais que realizamos nos auxiliam a acessar e a compreender circunstâncias que perfazem o trabalho com exemplares de textos no contexto de ensino-aprendizagem de língua de herança, o que, por sua vez, aponta para especificidades do trabalho do professor, que já atua ou quer atuar, nesse contexto.

PALAVRAS-CHAVE: Cultura; Língua de herança; Trabalho do professor; Texto como objeto de ensino.

\section{Introdução}

Nossos questionamentos sobre o lugar e natureza do trabalho com exemplares de gêneros textuais na sala de aula não são recentes, o que certamente coincide com a realidade

\footnotetext{
${ }_{1}^{1}$ Trabalho realizado com financiamento da Universidade Estadual do Sudoeste da Bahia (Uesb) e bolsa de pesquisa Uesb/Saeb (Secretaria da Administração do Estado da Bahia). Os dados, aqui publicizados, advêm de uma pesquisa de campo realizada na Alemanha, durante estágio pós-doutoral sob supervisão da Profa. Dra. Eulália Leurquin.

* Professora Titular da Universidade Estadual do Sudoeste da Bahia (Uesb). Doutora em Linguística e Língua Portuguesa pela Pontifícia Universidade Católica de Minas Gerais (Puc-MG). Coordenadora do projeto de extensão LaGaTT (Laboratório de Garimpo Textual e(m) Trabalho do professor de línguas) e líder do grupo de pesquisa LabCulTLet (Laboratório de Culturas, Trabalho e Letramento do professor).

** Professora Adjunta da Universidade Federal de São João del-Rei (UFSJ). Doutora em Linguística pela UFMG. Membro do Grupo de Pesquisa ENUNCIAR.

*** Professora Associada IV da Universidade Federal do Ceará (UFC). Doutora em Educação pela Universidade Federal do Rio Grande do Norte (UFRN). Líder do GEPLA/CNPQ (Grupo de Estudos e Pesquisas em Linguística Aplicada).
} 
de todo professor(a) de língua(s) nas últimas décadas. No entanto, nossas experiências profissionais mais recentes ${ }^{2}$ e o cenário geopolítico atual ${ }^{3}$ têm de algum modo nos levado a assumir uma posição teórico-metodológica ainda mais cautelosa, em nossas aulas, para a tematização do trabalho com textos/exemplares de gêneros.

Assim, do lugar sociointeracional de que examinamos a questão, como professoras formadoras atuantes em cursos de Letras, temos reivindicado uma tematização didática acerca do que se ensinar em gêneros e de como se ensinar a partir de textos que levem cada vez mais em consideração o lugar e a força de um contexto de ensino-aprendizagem.

Isso significa que reconhecemos não apenas um alargamento do espectro do trabalho do professor de línguas em outros e mais recentes contextos (que começam a ser cada vez mais conhecidos como: o de língua de acolhimento, língua adicional e língua de herança, somados aos, já referencialmente consolidados, contextos de língua materna, língua estrangeira, segunda língua - Modl e Leurquin, 2018), mas visualizamos ainda a urgência de que aproximações e afastamentos entre o trabalho do professor de português nesses contextos sejam cada vez mais pesquisados e didatizados nas formações iniciada e continuada do professor de línguas. Ora, ao afirmar isso, estamos, sim, também dizendo que há aí questões ainda silentes na e para a pauta das agendas de formação do professor, o que nos lembra de que tanto didatizamos pesquisas, quanto as realizamos a partir de necessidades de didatização (ZANDWAIS, 2012).

\footnotetext{
${ }^{2}$ Destacamos, aqui, um conjunto de ações de docência e pesquisa voltadas aos contextos de ensino-aprendizagem de português como língua estrangeira e de português como língua de herança encampadas no Programa de Extensão "Laboratório de Línguas: ensino, aprendizagem e formação do professor" (UFC/CNPQ) da Universidade Federal do Ceará (UFC)-Brasil e mais recentemente, desde 2019, no LaGaTT (Laboratório de Garimpo Textual $\mathrm{e}(\mathrm{m})$ Trabalho do professor de línguas) da UESB em parcerias interinstitucionais com UFSJ, UFC, UFTO, UNEB e Sesi Unidade Sudoeste/ Escola Sesi Anísio Teixeira, bem como a experiência de ensino de português com norteamericanos no convênio UFSJ- FLAGSHIP/UGA, e outras instituições de ensino no Brasil e exterior.

${ }^{3}$ Ao dizer cenário geopolítico atual, estamos considerando experiências humanas interculturais aí previstas em processos como internacionalização, transferências de sujeitos que atuam em empresas multinacionais no Brasil para sedes de empresas no exterior, por meio de políticas de expatriados, crises migratórias, motivadas por razões diversas ou mesmo casamentos interculturais e, consequentemente, o que isso provoca em termos do contato de sujeitos brasileiros fora do país com outras culturas e línguas, contribuindo para demandas de outros contextos de ensino-aprendizagem de línguas.
} 
Os dados que aqui apresentamos são provenientes de um corpus de uma pesquisa qualitativa de natureza etnográfica (ERICKSON, 1990), realizada ao longo de 18 meses, em uma escola de língua de Português como Língua de Herança (doravante PLH) e culturas brasileiras, situada no estado da Bavária, na Alemanha.

Como material de análise, apresentamos duas cenas transcritas de uma aula em que uma professora brasileira interage a partir de uma atividade didática com seus alunos germânico-brasileiros sobre uma propaganda verbo-visual impressa.

A leitura que fazemos dos dados evidencia como conhecimentos (inter)culturais dos alunos, acionados por questões vinculadas a léxico e(m) referenciação, explicam o modo como eles leem a propaganda/objeto de ensino da aula, o modo como a professora reage a essa leitura, bem como nós, as autoras, interpretamos tudo o que acontece nas interações em exame, buscando realizar generalizações que nos informem sobre o contexto de ensino-aprendizagem de língua de herança.

Para chegar à demonstração de nossos achados, o trabalho se organiza em mais três seções. Na próxima seção, Fundamentação conceitual, esclarecemos a que nos referimos ao dizer cultura e léxico, assim como trazemos a noção de território, que para nós é um conceito da Geografia que se filia à compreensão intercultural do fazer e dar aulas e do modo como os sujeitos apreendem a lidar com suas línguas de contato. Evocamos tais noções para tematizar aspectos que ligam a língua de herança ao modo como o tratamento do seu falante aparecem tematizados na literatura específica. Fazemos a opção de já irmos adiantando, ao longo da seção teórica, aspectos que informam sobre os sujeitos que protagonizam as cenas adiante analisadas. O que fazemos não apenas por questões de espaço, mas porque acreditamos que assim conseguimos dar mais visibilidade à interface entre as escolhas teóricas que realizamos e algumas das especificidades dos sujeitos que protagonizam as cenas, conferindo traços às suas identidades linguísticas.

Já a seção Dados (re)velados assume uma dupla-função: a de sumariamente informar sobre a ambientação acadêmica da pesquisa, mais ampla, de que extrato do corpus é proveniente e a de acolher a análise que realizamos, procurando traçar a interculturalidade como elemento fulcral da natureza do trabalho do professor no contexto. 
Encerramos o trabalho explicitando aspectos que acenam para a complexidade e, ao mesmo tempo, necessidade de tematizarmos a ampliação do espectro de atuação do professor de línguas na contemporaneidade via achados da pesquisa realizada em um contexto de ensino-aprendizagem de língua de herança.

\section{Fundamentação conceitual}

Hancock (2018, p. 182), tematizando sobre a implicação do sujeito pesquisador em campo de pesquisa, afirma que "it provides a way of conceptualizing and mapping precisely how social structure gets 'inside' actors". Como essa estrutura social é entronizada pelos sujeitos, interessa-nos, no presente trabalho, porque essa estrutura se deixa (entre)ver no repertório linguístico-discursivo de que se valem alunos e professora para lerem a propaganda-objeto de ensino. Afinal,

[...] the things people say offer, certainly not an unproblematic record of the cultural understandings that people have in mind when they say them, and certainly not the only record of these shared understandings, but simply the fullest and most decipherable record available..$^{5}$ QUINN, 2005, p. 4)

As línguas alemã (materna) e o português (língua de herança) ${ }^{6}$ de que se valem os alunos, que protagonizam as cenas da aula-objeto de exame, e o modo como eles interpretam o texto-objeto de leitura, a partir do repertório lexicogramatical que mobilizam para

\footnotetext{
4 Tradução nossa: "Isso fornece uma maneira de conceituar e mapear com precisão como a estrutura social 'entra' nos atores" (HANCOCK, 2018, p. 182).

${ }^{5}$ Tradução nossa: “As coisas que as pessoas dizem oferecem, certamente não um registro não problemático das compreensões culturais que essas pessoas têm em mente quando as dizem, o que certamente não o único registro dessas compreensões compartilhadas, mas simplesmente o registro mais completo e mais decifrável disponível". (QUINN, 2005, p. 4)

${ }^{6}$ A expressão Língua de Herança (LH), usada pela $1^{\text {a }}$ vez no Canadá nos anos 70 (Cummins, 1983), só começa a ser mais referenciada na Europa no início dos anos 80 (Guardado, 2018) e a ser objeto de políticas de pesquisas e financiamentos públicos nos Estados Unidos nos anos 1990 (HORNBERGER; WANG, 2008). Diversos autores já reconhecem que a LH foi largamente negligenciada pela Linguística Aplicada (OXFORD 1982, MERINO 1983, PAN; BERKO-GLEASON 1986, WONG; FILMORE 1991).
} 
expor suas interpretações, informam sobre os processos de referenciação que lá são construídos.

Vemos no intrincado processo de referenciação, um modo de se pensar e visualizar essa estrutura social a que se refere Hancock (2018) "inside"/ "nos" sujeitos, ou seja, cognitivamente implicada.

Sujeitos que têm uma língua de herança vivenciam necessariamente a interculturalidade. Isso porque "tipicamente são considerados falantes de herança os imigrantes de $2^{\mathrm{a}} \mathrm{e}$ $3^{a}$ geração que cresceram no país de acolhimento tendo como língua dominante a língua da sociedade de acolhimento" (FLORES; BARBOSA, 2011, p. 82), sendo a língua de herança a língua materna do pai, mãe ou dois pais imigrados para o país onde o falante de herança nasceu e/ou cresceu. Nisso, já começamos a visualizar como o contexto de língua de herança é naturalmente intercultural.

Tomando cultura como "the collective programming of the mind that distinguishes members of one society form another- the accumulation of shared meaning, rituals, norms, and traditions among members of a society (Solomon, 1996)." (WOODSIDE, 2010, p. 363), a aula de português como língua de herança precisa figurar um lugar institucional para se acessar, via trabalho com exemplares de diferente gêneros textuais, práticas culturais autênticas, que estão circulando entre brasileiros, nos mais diferentes circuitos interlocutivos, e delimitando modos de se conviver socialmente, a partir de modos de dizer/agir (re)produzidos culturalmente por falantes brasileiros.

Esses modos de dizer/agir culturalmente reproduzidos por falantes de uma determinada língua materializam a íntima relação entre cognição, gramática internalizada e cultura. O que nos relembra da abordagem interpretativa de Geertz (1973) sobre cultura:

The concept of culture I espouse [...] is essentially a semiotic one. Believing, with Max Weber, that man is an animal suspended in webs of significance he himself has spun, I take culture to be those

\footnotetext{
${ }^{7}$ Em nossa tradução: "A programação coletiva da mente que distingue os membros de uma sociedade de outraa acumulação de significados compartilhados, rituais, normas e tradições entre os membros de uma sociedade (Solomon, 1996)." (WOODSIDE, 2010, p. 363).
} 
webs, and the analysis of it to be therefore not an experimental science in search of law but an interpretive one in search of meaning ${ }^{8}$. (GEERTZ 1973, p. 5)

Se "language must be understood as cultural practice"9 (Duranti, 2015, p. 23), o autor esclarece que:

Geertz's view of culture focuses on culture as a product of human interaction - "culture [...] is public [...] it does not exist in someone's head [...]" (Geertz, 1973). Human beings both create culture and must interpret it. To say that culture is not in someone's head means to emphasize the fact that culture is out there, both produced by and available to humans for interpretation. In this perspective, cultural manifestations are acts of communication. When we observe people engaged in a public debate, participating in a funeral, going to a soccer match, or watching a cock fight, we see people engaged in coordinated behaviors which not only imply but also produce worldviews, including local notions of person (or self), a concept that is central to Geertz's work as well as to much of cultural anthropology. ${ }^{10}$ (DURANTI, 2015, p. 36)

É justamente nesse tipo de busca por situar o sujeito que fala/interpreta na cultura que lemos como ponto de interface entre trabalhos em antropologia linguística (como os de Geertz e Duranti) e o tratamento vertido às noções de gênero de discurso/discursivo/textual por tantos teóricos no cenário brasileiro e internacional nas áreas de Linguística Textual, Análise do Discurso e sobretudo em Linguística Aplicada cujo compromisso se volta também à didatização e a circulação de saberes de referência na formação do professor:

\footnotetext{
${ }^{8}$ Em nossa tradução: “O conceito de cultura que eu defendo [...] é essencialmente semiótico. Acreditando, com Max Weber, que o homem é um animal suspenso em teias de significância que ele mesmo tem, eu levo a cultura para integrar essas teias, e a análise disso para ser, portanto, não uma ciência experimental em busca de reconhecimento/autorizo, mas uma ciência interpretativa em busca de significado". (GEERTZ 1973, p. 5)

${ }^{9}$ Em nossa tradução: “se língua/linguagem deve ser entendida como prática cultural” (DURANTI, 2015, p. 23).

${ }^{10}$ Tradução nossa: “A visão de Geertz da cultura se concentra na cultura como um produto da interação humana - "a cultura [...] é pública ... ela não existe na cabeça de alguém ..." (Geertz, 1973). Os seres humanos criam cultura e devem interpretá-la. Dizer que a cultura não está na cabeça de alguém significa enfatizar o fato de que a cultura está lá fora, tanto produzida quanto disponível para os humanos para interpretação. Nesta perspectiva, as manifestações culturais são atos de comunicação. Quando observamos pessoas envolvidas em um debate público, participando de um funeral, indo a uma partida de futebol ou assistindo a uma briga de galo, vemos pessoas engajadas em comportamentos coordenados que não apenas implicam, mas também produzem visões de mundo, incluindo noções locais de pessoa (ou self), um conceito que é central para o trabalho de Geertz, bem como para grande parte da antropologia cultural. (DURANTI, 2015, p. 36).
} 
Fazer com que os resultados dos estudos a respeito da natureza da linguagem, de seu papel na vida humana, nos seus mais variados aspectos, sejam postos a serviço da humanidade é não só o papel da LA e o dever de quem nela trabalha, mas é também acima de tudo, a vocação desta área fascinante do saber. (CELANI, 2000, p. 32)

Destacamos a ligação de interculturalidade e de cultura também conectada à visão dos estudos sobre territórios para além da Geografia, tomando-o como apropriação simbólica (STÜRMER ; DA COSTA, 2017). Para nós, território é visto como um campo simbólico de compreensão da atividade humana que marca dois aspectos: a relação do homem com o espaço e como ele se organiza construindo suas próprias estratégias (por práticas, por exemplo) para lidar com esse espaço. Defendemos que um território não se faz somente como espaço geográfico (tal como se dá a acepção do termo tradicionalmente): se traduz, pois, à absorção e ressignificação do conjunto simbólico de regularidades e de regras compartilhadas entre participantes de instituições que resvalam nas práticas interacionais e nas relações efetivadas a partir do exercício ainda que fluido do poder. Esse caminho é trilhado pelos falantes por meio do modo como a língua de herança se efetiva, na compreensão e na (re)elaboração das práticas e das relações entre dois caminhos, entre dois territórios, o da própria língua que é, também, a língua do outro. Acreditamos, pois, lidar com territorialidades, ações/construtos a partir das marcas simbólicas de territórios em contato, indica certa condução de comportamentos no dialogar entre territórios. Tal território se dá na instância geográfica, mas se dá pelo modo como os sujeitos constroem sentido de pertencimento a um ou outro local, sendo falante de uma ou outra língua. A língua de herança se dá, portanto, dotada de sentidos, e o território se faz em um conjunto de relações projetadas ou perpassadas pelas relações de poder, nas relações sociais (HAESBAERT, 2004, p. 78).

É a esse lugar político-interacional da/em Linguística Aplicada que se efetiva em seu campo inter/indisciplinar (MOITA LOPES, 2006), que se dedica ao campo da formação do professor, que fazemos coro ao entendermos que gêneros traduzem modos culturais de e para se (com)portar em sociedade. Afinal, é no e pelo trabalho com textos que 
processos de (res)significação tão caros às aulas de língua ocorrem. "A tomada de consciência em relação à diversidade linguística e enunciativa é um fator crucial para as transformações simbólico-identitárias inerentes ao processo de ensino-aprendizado" (SERRANI, 2005, p. 34) e "o aprendizado dos gêneros representa um processo de socialização do aprendiz nos modos de organizar o conhecimento e a maneira de representar suas percepções e seu conhecimento para os outros.” (PINTO, 2002, p. 49).

Dentre as especificidades do contexto de língua de herança, insistimos na presença da noção de interculturalidade, porque acreditamos no que Ochs toma como um sistema de conhecimentos e crenças que acabam por habitar a sala de aula:

Knowledge and beliefs about the world held by interlocutors are not limited to entities and behaviors that are part of local utterance environment. Interlocutors have awareness of and assumptions about objects, events, and states of affairs outside the interactional settings, and these affect how language is used and understood. ${ }^{11}$ (OCHS, 1979, p. 4)

A aula de língua de herança, como espaço de enunciação do aprender, figura necessariamente lugar para se distanciar dessa enunciação local (sempre cultural!) a que se refere Ochs (1979), conferindo espaço para que, via trabalho com textos autênticos que circula(ra)m em enunciações locais (culturais brasileiras!), se possa trabalhar a "capacidade do aluno de reconhecer as convenções deste gênero em determinada língua ou cultura." (ANDRADE, 2017, p. 4).

Estamos falando, aqui, também que o contexto de LH requer que compreendamos que:

[...] a quantidade e a qualidade de input que o falante de herança recebe na sua língua de herança diferem consideravelmente do input presente na aquisição monolíngue ou no bilinguismo simultâneo. Em geral, o falante de herança não é escolarizado na sua língua de

\footnotetext{
${ }^{11}$ Em nossa tradução: “Os conhecimentos e crenças sobre o mundo mantidos pelos interlocutores não se limitam a entidades e comportamentos que fazem parte do ambiente de enunciação local. Os interlocutores têm consciência e suposições sobre objetos, eventos e estados de coisas fora dos ambientes interacionais, e estes afetam como a linguagem é usada e compreendida." (OCHS, 1979, p. 4).
} 
herança ou, se o é, tem um nível de educação formal muito baixo nesta língua. (FLORES; BARBOSA, 2011, p. 81).

Em termos da política linguística familiar, no que respeita à exposição quanti e qualitativa de input a que os alunos da Escola-campo de pesquisa estiveram e estão continuamente expostos, um levantamento realizado apontou que dos 41 mães e pais brasileiros dos alunos da Escola, matriculados no período da pesquisa, 9 deles declaram falar exclusivamente português com os filhos, desde o nascimento deles. Dos 41, 16 informaram-nos que passaram a falar português tardiamente com os filhos, o que coincide com o período em que eles matricularam o filho na Escola-campo de pesquisa e outros 16 esclarecem que optaram por falar exclusivamente a língua alemã.

Esses mães e pais brasileiros dos alunos da Escola esperam que, processualmente, seus filhos desenvolvam habilidades linguísticas que os permitam ler e escrever em português, bem como que esse falar se dê com o mínimo de sotaque possível e que esse falar/escrever seja feito respeitando-se a variante padrão do português brasileiro.

Esse cenário que acabamos de descrever faz eco ao modo como as linguistas Flores e Barbosa entendem como o perfil linguístico do falante de herança:

Não é possível descrever os falantes de herança como um grupo homogéneo. O nível de proficiência que um falante de herança apresenta pode variar de 'muito básico' a 'muito elevado', pois são muitos os factores que influenciam a competência do falante bilingue a nível da sua língua de herança. A exposição à língua maioritária pode ocorrer em paralelo à língua de herança (bilinguismo simultâneo) ou após a criança ter adquirido a língua da família (bilinguismo sequencial). A língua maioritária pode ser totalmente excluída da interacção familiar, estar presente na comunicação entre irmãos ou ser usada em simultâneo com a língua da família pelos pais. Além disso, nem todos os falantes de herança têm a possibilidade ou a vontade de frequentar aulas na sua língua de origem. (FLORES; BARBOSA, 2011, p. 82)

A Escola-campo de pesquisa funciona como curso de língua de herança aos sábados. O que Duff (2008) resenha como a natureza do funcionamento mais prototípico para cursos de língua de herança (Saturday Heritage Language-HL) no mundo, ao lado dos cursos que ocorrem depois da Escola (After school). 
A Escola funciona desvinculada de políticas públicas governamentais específicas para língua de herança, sendo fruto de uma Associação sem fins lucrativos formada por pais brasileiros e germânicos e professores brasileiros residentes na cidade em que está sediada a Associação. Esse cenário de ensino-aprendizagem de língua de herança é, mais uma vez, o contexto mais comum de políticas de LH/HL, conforme levantamento de autores como Guardado (2018).

No ano letivo alemão 2018-201912, a Escola contava com 44 alunos matriculados e ofereceu 5 diferentes cursos, com carga horária total de 66h-aula cada, fracionada em 3haula por sábado letivo e promoveu 6 eventos culturais (comemoração de festas brasileiras concomitantes ao calendário brasileiro).

Os cursos se voltam a alunos em idade escolar que descendem, em sua maioria, de casamentos interculturais, sendo que, em termos identitários relativos à descendência (todos de $2^{a}$ geração) e cidadania, temos que dos 44 alunos matriculados:

a) $\underline{36}$ alunos descendem de casamentos biculturais, o que representa $90 \%$ do alunado da Escola.

aa) dos 33 desses alunos, 26 deles têm a mãe brasileira e o pai alemão e outros 7 o contrário: o pai brasileiro e a mãe alemã. Nesse grupo, todos os 33 alunos têm cidadania alemã e brasileira.

aaa) outros $\mathbf{3}$ alunos têm a cidadania brasileira e uma segunda que não a alemã. Nesses casos, esses alunos têm a mãe brasileira e o pai dos Estados Unidos, Filipinas ou Itália.

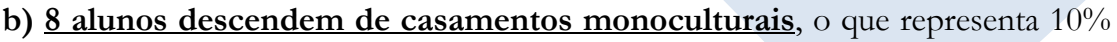
do alunado da Escola.

bb) $\mathbf{5}$ dos alunos têm apenas cidadania brasileira, porque têm o pai e a mãe brasileiros ${ }^{13}$.

\footnotetext{
$12 \mathrm{O}$ ano letivo alemão, no estado da Bavária, compreende o período de setembro a julho.

13 Aqui, enquadram-se apenas os filhos das professoras da Associação matriculados na Escola.
} 
bbb) 3 dos alunos desse grupo têm apenas cidadania alemã, o que significa que têm o pai e a mãe alemães ${ }^{14}$.

As 5 turmas são constituídas por alunos de 3 a 16 anos. Temos, protagonizando as cenas de aula, na próxima seção, alunos entre 13 e 16 anos, portanto do último curso oferecido pela Escola. As turmas são organizadas levando-se em consideração a idade dos alunos, que têm habilidades linguísticas bastante diversas, como é previsto na literatura específica:

$\mathrm{Na}$ literatura, o falante de herança é geralmente definido como indivíduo bilingue que tem competência produtiva a nível da sua língua de herança, mas essa competência difere da competência linguística de falantes nativos da mesma idade, grupo social e desenvolvimento cognitivo (Montrul, 2010; Rothman, 2007). (FLORES; BARBOSA, 2011, p. 82)

Dentre os 44 alunos, apenas os 3 alunos alemães (filhos de pais alemães) já moraram no Brasil, tendo, por isso, vivência na cultura escolar brasileira. Todos os outros 41 alunos têm vivência exclusiva na cultura escolar alemã ${ }^{15}$. Essa informação importa por diversas razões, dentre elas, destacamos o input quanti e qualitativo de português a que os alunos estão e estiveram expostos, o que certamente é uma informação cara para se considerar seus conhecimentos linguísticos de gramáticas, compreendidas como conjunto léxico-gramatical para referenciar "um conjunto de símbolos interconectados por um conjunto ordenado de regras" que figuram "propriedade de qualquer idioma" (PONTARA; CRISTOVÃO, 2017, p. 880), realçando que o contexto de LH coloca em interface gramáticas internalizadas, compreendidas como: "conjunto de regras que o falante domina - refere-se a hipóteses sobre os conhecimentos que habilitam o falante a produzir frases ou sequências

\footnotetext{
${ }^{14} \mathrm{O}$ que não os caracteriza como falantes de língua de herança. No entanto, como esse grupo tem vivência no Brasil e na cultura escolar brasileira, os cursos de português como língua estrangeira figurariam um lugar menos afetivo para o Grupo. Argumentação essa que fez a Escola flexibilizar a matrícula, compreendendo que se trata de uma herança simbólica.

15 Ao se falar sobre cultura escolar local, questões dessa ordem importam, porque se deixam entrever em comportamentos linguístico-discursivos diversos na aula (Modl e Biavati, 2016; Modl, 2017) de língua de herança.
} 
de palavras de maneira tal que essas frases e sequências são compreensíveis e reconhecidas como pertencendo a uma língua.” (POSSENTI, 1996, p. 67-68).

Ao mesmo tempo, ao lidar com aspectos da interculturalidade, o aluno é desafiado a tomar para si as práticas do outro, de pertencimento, os regramentos que se dão a partir da observação dos elementos que juntam ou que podem desafiar os falantes ao lidar com representações e comportamentos diferentes em dois territórios.

Cabe somar, a essa conta da gramática internalizada, a cultura linguística desse alunado que

should therefore be seen as an inherent part of learning, which needs to be incorporated into linguistic policies and teaching methods. These methods must reconcile a priori apparent conflicts between the need for a self-centred focus and a grounding in the familiar, on the one hand, and the broad-mindedness that is essential in order to learn languages, on the other. ${ }^{16}$ (CASTELLOTTI; MOORE, 2002, p. 20).

A necessidade de entender que as imagens que professora e alunos têm/trazem para a aula de LH compõem essa cultura linguística que pode se deixar entrever também no modo como sujeitos de diferentes culturas significam itens de um léxico e destacam ações e regramentos a partir dos territórios de pertença, como procuramos demonstrar, na sequência, na análise.

\section{Dados (re)velados}

A aula de que advém a cena (dividida em suas partes) que passamos a analisar foi planejada coletivamente entre uma das professoras-sujeito da pesquisa e a pesquisadora como atividade do curso ${ }^{17}$ "Formação docente e $(\mathrm{m})$ contexto de ensino-aprendizagem de

\footnotetext{
${ }^{16}$ Traduzindo: "deve, portanto, ser visto como uma parte inerente da aprendizagem, que precisa ser incorporada às políticas linguísticas e aos métodos de ensino. Esses métodos devem conciliar conflitos aparentes a priori entre a necessidade de um foco egocêntrico e a ancoragem no familiar, por um lado, e a mentalidade aberta que é essencial para aprender línguas, por outro". (CASTELLOTTI; MOORE, 2002, p. 20).

${ }_{17} \mathrm{O}$ tempo de 18 meses em campo foi suficiente para que uma convivência afetiva fosse estabelecida entre Fernanda Modl e as professoras da Escola-campo de pesquisa. A boa relação da pesquisadora com o grupo de professoras foi processualmente sendo construída, ao longo dos meses de observação das aulas, à medida que a professora-pesquisadora ia demonstrando sua curiosidade para estudar e compreender o trabalho do professor 
língua de herança" promovido e certificado em parceria com o "Programa de Extensão Laboratório de Línguas: Ensino, Aprendizagem e Formação do Professor“(UFC/CNPQ) sob coordenação de Eulália Leurquin.

A atividade se prestava ao trabalho de calibragem de dois princípios de trabalho, que haviam sido coletivamente estudados no Curso e que começavam a ser entendidos pelo grupo de professoras, quais sejam:

1) o trabalho com textos autênticos, por meio da escolha didática de um exemplar de gênero (aqui a propaganda verbo-visual impressa) para o desenvolvimento de competências linguístico-discursivas diversas; e

2) a sensibilidade pela tematização da interculturalidade, que atravessa tanto o trabalho de leitura do texto-objeto de ensino por professora e alunos, a

no contexto de língua de herança, as professoras-sujeitos da pesquisa iam se abrindo e conversando com a pesquisadora sobre aquilo que elas consideravam ser as suas fragilidades didáticas. As observações processuais de aulas de diferentes professoras haviam sinalizado para a percepção da pesquisadora, que foi posteriormente confirmada pelo grupo de professoras e pela coordenação pedagógica, de que não haviam princípios teórico-metodológicos compartilhados por toda a equipe de professoras. De uma reunião de trabalho com a coordenação pedagógica para mostra de impressões iniciais das observações em campo, veio o pedido de que um curso de formação para as professoras fosse preparado a partir das ressonâncias do que a pesquisadora (como professoraformadora de professores no Brasil) pensava ser necessário em termos teórico-metodológicos para o Grupo. A pesquisadora em campo foi surpreendida com o pedido, uma vez que antes da entrada em campo, nossa intenção era estudar a performance linguística de falantes de língua de herança, o que significa considerar que estávamos interessadas na observação, no cenário linguístico da aula e das socializações que ali se descortinam, de ocorrências/formulações linguísticas que nos auxiliassem a compreender aspectos vinculados ao Desenvolvimento (Development), Manutenção (Maintenance) e/ou Perda (Loss) do português brasileiro como língua de herança. O pedido da equipe pedagógica de um curso de formação foi, assim, um divisor de águas para que percebêssemos o quão ainda incipiente são os trabalhos em língua de herança que se voltam à formação do professor para atuar nesse contexto. Um extenso e recente levantamento realizado por Guardado (2018) sobre os enquadres mais recorrentes de pesquisa em LH atestam que, na literatura da área, são 4 as vertentes mais estudadas, nesta ordem de recorrência temática: 1) razões familiares para o desenvolvimento da língua de herança; 2) o papel e o efeito do desenvolvimento da língua de herança para as famílias; 3) atividades e estratégias utilizadas pelas famílias para o desenvolvimento da língua de herança e 4) o papel das identidades linguísticas. Apesar de entendemos que o desenvolvimento expressivo de estudos vinculados a esses quatro enquadres sinaliza um movimento natural e necessário para a compreensão do campo da língua e falante de língua de herança, isso é mais um argumento para se aceitar $\mathrm{s}$ urgência de que dados advindos de pesquisas como essas e de outras pesquisa na área de Linguística, que se voltam à compreensão de fenômenos linguísticos específicos sejam lidos e didatizados por nós em Linguística Aplicada. Consumo da literatura esse que, a nosso ver, precisa ser realizado concomitantemente com investidas de pesquisa de/em campo em interlocuções com professoras que atuem no chão da sala de aula de língua de herança. O curso a nós solicitado foi, então, preparado, via dialogia em reuniões de trabalho entre Fernanda Modl e Eulália Leurquin e a coordenação pedagógica da Escola. 
própria configuração do gênero-objeto de exame, bem como o modo como se comportam professora e alunos em sala de aula.

A seguir, vemos o modo como a propaganda foi apresentada aos alunos em atividade didática.

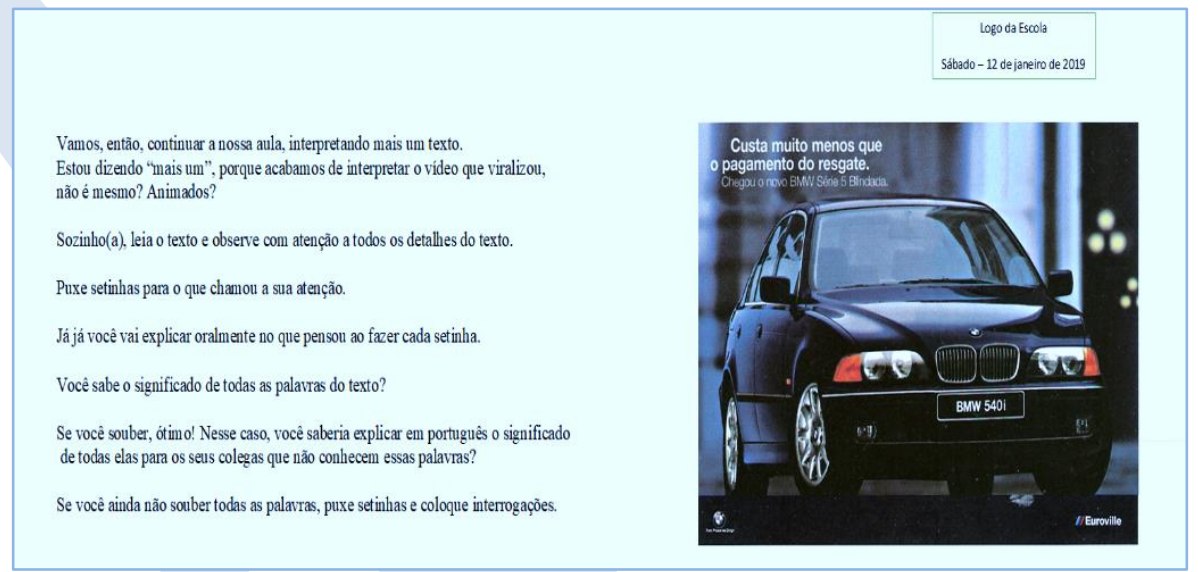

Em momento que antecedeu a aula, quando a pesquisadora e a professora brasileirasujeito da pesquisa (a que chamaremos de Marta ${ }^{18}$ ) conversaram sobre o exemplar impresso da propaganda, refletindo sobre a produtividade ou não de se tomar a propaganda acima como objeto de ensino, Marta afirmou: "não visualizo ainda muita coisa para ser trabalhada com este texto". As interlocuções foram ocorrendo até que chegássemos ao planejamento inicial nos valendo do exemplar da propaganda para uma aula de leitura verbo-visual que colocasse em foco uma reflexão sobre o enunciado "Custa muito menos que o pagamento do resgate" e discutir sobre a riqueza dos implícitos indiciados no enunciado, bem como promover reflexões mais interculturais indiciadas na gramática das duas línguas e no modo como as sociedades alemã e brasileira produzem o gênero propaganda.

\footnotetext{
${ }^{18}$ Esse nome, assim como o de todos os alunos que protagonizam as cenas adiante são fictícios. Optamos apenas por manter como traço identitário a origem dos nomes reais dos sujeitos. Por exemplo, se uma aluna tivesse um nome de origem francesa como Chlòe a chamamos, aqui, de Marie. Ou um nome tipicamente alemão como Hans poderia ser substituído por outro como Clement.
} 
Embora toda a transcrição da aula seja especialmente interessante, por questões de espaço, escolhemos uma cena da aula que nos auxilia a exemplificar a nossa percepção (gerada a partir de um longo período em campo junto a 7 professoras) de especificidades do contexto de ensino-aprendizagem de língua de herança e a sintetizar, na forma de apontamentos, aspectos vinculados ao trabalho com língua(gem) nesse contexto.

Passemos às cenas de sala de aula.

\section{CENA DE SALA DE AULA - parte 1}

13 Aluna Marie: O que é resgaste?

14 Professora Marta: Ta coloca primeiro as suas dúvidas ó... a gente já vai responder...deixa...é... um ponto...circula puxa uma setinha e coloca um ponto de interrogação... que eu já falo... (os alunos têm expressões faciais tensionadas, enquanto olham para o papel) Tirando a palavra resgate... tem mais alguma que vocês não sabem? (aluno levanta a mão) fala...

15 Aluno Mark: Eu queria perguntar se (aluno lê) “o BMW série 5 blindada” é o nome ou não?

16 Professora Marta: O que é blindado?

17 Aluno Mark: é quando tem um... a janela é... é...

18 Professora Marta: que é inquebrável... ou quando você dá tiro... nem todos os...nem atravessam...é blindado... ... e o resgate... quem sabe falar o que é o RESGATE em português ... que eu vi que a Marie deu uma traduzida sussurrando baixinho aí para o alemão...eu quero a explicação em português...(o aluno Hans se candidata levantando a mão direita) vai Hans

19 Aluno Hans: É... são pessoas que... se você tem um problema...é: é... de... ajuda Anne (pedindo auxílio a uma colega de turma sentada próxima a ele)

20 Professora Marta: vai tenta

21 Aluno Hans: hum a... não sei explicar

22 Professora Marta: Vamos ver! Felix (passando a palavra aleatoriamente para os alunos que ainda não se pronunciaram na aula)

23 Aluno Felix: Resgate é quando você: é... preciso de... (aluno ri, porque também não consegue explicar)

24 Professora Marta: Valentina

25 Aluna Valentina: É quando alguém te salva...eles fazem um resgate

26 Professora Marta: Isso...era isso que você queria dizer Hans? te ajudaste? Quer complementar?

27 Aluno Hans: Aham ... por exemplo uma ambulância

28 Professora Marta: isso...é um resgate...isso

29 Aluno Max: Resgatar alguém

30 Professora Marta: mas aí ó... prestem eu quero que vocês PRES-tem atenção no CONtexto... humm (aluno Pirm se candidata) fala!

31 Aluno Pirm: Então...eu acho que eles querem que... que a gente compra esse carro...porque eles dizem que: custa MENOS comprar esse carro blindado...do que pagando a ambulância que tem que: salvar a sua vida se você é machucado...

32 Professora Marta: hu...m (fazendo som de dúvida e, ao mesmo tempo, surpresa, o que soa como um som de meditação) 
33 Quase todos os alunos: riem e alguns se divertem emitindo o som

\section{CENA DE SALA DE AULA - parte 2}

34 Professora Marta: hum é: ó: hum... é uma dedução perfeita (referindo-se ao que Pirm diz no turno 31) talvez para um a: é que você está sendo ingênuo na sua dedução...mas mas acho que num contexto alemão teriam que usar isso porque não faz muito sentido porque não vai custar menos do que um carro blindado... o carro blindado não vai custar menos do que uma ambulância te resgatando indo te resgatar... não vai ..com certeza... você Valentina...como você interpreta?

35 Aluna Valentina: Não sei... mas...é... as vezes... é: tem isso se você bate o carro e se o carro não funciona...é... o... o aquele caminhão que pega os carros

36 Professora Marta: ah o guincho?

37 Aluna Valentina: É o guincho

38 Professora Marta: Você acha que o guincho vai custar mais que o carro blindado? (Valentina olha com expressão de dúvida, assim como os outros alunos) ... você (endereçando a palavra a Peter)!

39 Aluno Peter: Acho que é o seguro

40 Professora Marta: do quê? do carro blindado? Você acha que o seguro ... o resgate aí... seria o seguro? O seguro custa mais do que o carro blindado (os alunos olham com expressão facial de dúvida)

41 Professora Marta: Hum ... não (respondendo com entonação firme, mas com expressão facial descontraída. Quase todos os alunos riem diante da resposta negativa da professora)

42 Aluno Pirm: Então não é nada disso?

43 Professora Marta: não...são intepretações naturais de vocês fazerem...eu também faria se eu tivesse sempre vivido na Alemanha...mas não...não é isso... ... ... alguém tem alguma alguma teoria diferente?

44 Aluno Pirm: Humm talvez porque o Brasil é um pouquinho mais gefahrlich é... como é que chama é...

45 Aluno Felix: perigoso

46 Aluno Pirm: É isso perigoso

47 Professora Marta: É por esse lado... é por esse lado do perigoso

48 Aluno Hans: É por isso porque eu disse da ambulância...se alguém tem uma machuca... eles shootão em você e o carro te salva (Angelina se candidata para falar, levantando a mão direita)

49 Professora Marta: fala

50 Aluna Angelina: Talvez o carro custa muito menos que a própria vida

(alunos mostram sinal de espanto)

51 Professora Marta: ah é... ó... olha... é uma boa intepretação... mas não é: é: eu tenho certeza que eles não pensaram nesse sentido...o que você ia falar? Então... quando eles falam PAGAMENTO do resgate... eles se referem a condição de sequestro ... SE-QUESTRO... sabem o que é sequestro? (alunos olham com expressão de dúvida) não sabem? Eu não sei se... eu vou explicar e vocês me falam se tem uma palavra em alemão porque agora eu fiquei curiosa

52 Alguns alunos respondem: Entführung (traduzindo para o português: rapto, sequestro)

53 Professora Marta: Entführung? ela falou que é isso... é quando uma pessoa... os bandidos veem e levam a pessoa com eles e aí entram em contato com a família pedindo que a família pague que é para a pessoa seja devolvida (alunos murmuram anham) isso é SEQUESTRO... o que o bandido praticou é o sequestro...então quando ele fala custa muito menos que o pagamento do sequestro... não é só em termos financeiros que ele está falando... mas ele ta falando de toda a questão emocional ...tá? porque porque geralmente o que eles fazem? Geralmente eles pegam a pessoa ... levam a pessoa para um lugar afastado...em condições MUITO ruins...em condições péssimas...às vezes as pessoas ficam em lugares escuros...sem janelas...afastado porque se ela gritar ninguém vai ouvir ela...você nunca viram filme de resgaste... de sequestro? (alunos respondem que sim) então isso acontece de fato no Brasil... quer dizer custa muito menos que o pagamento do resgate e: e muitas vezes eles 
pedem quantias que são ABSURdas ABSURDAS... realmente é um dinheiro que às vezes você não tem pra pagar... às vezes tem gente que vende as coisas da casa pra pagar o resgate... no Brasil às vezes tem muito também de ligar enganando "Olha eu tô aqui com o seu filho"

54 Aluno Felix: É a minha avó foi... ela mora no Brasil... eles ligaram para a minha avó e disse tô com a filha ... aí minha avó pensou ahan ela mora na Alemanha (Muitos alunos riem)

55 Professora Marta: é: tiveram azar, né? Tiveram azar no caso

56 Aluno Felix: Aí minha avó disse...pode ficar com ela aí que não tem problema (Muitos alunos riem)

Considerando outros princípios tematizados no Curso de formação como o lugar da dialogicidade e da interatividade no e para o gerenciamento da aula, as cenas registram uma boa alternância dos turnos de fala entre professora e alunos da turma na interação principal e ausência de microinterações, pistas interacionais importantes para se acessar o engajamento interacional do grupo de alunos na atividade de leitura.

Como as duas partes da Cena ilustram, tomar como objeto de análise coletiva um exemplar de propaganda do contexto brasileiro chega a desafiar os alunos-interlocutores do/no território alemão, pois facilmente esse exercício analítico nos leva à rede de condutas que marcam as territorialidades brasileiras.

Ao enunciar a propaganda, o desafio referencial da turma se deu por meio de o levantamento de várias hipóteses de leituras, ancoradas no (des)conhecimento do grupo de dois itens lexicais centrais para a interpretação (resgate e blindada).

A construção do caminho referencial sobre/para discursos sobre segurança nacional, compreendendo, por exemplo, como se consolidam as noções de "comprar carro blindado" em vez de "pagar resgate" e de que maneira tais práticas acabam por ser naturalizadas no Brasil e, consequentemente, na interpretação de falantes de português (como língua materna ou não), mas que, por residirem no Brasil, lugar de circulação original da propaganda, estariam mais expostos e mais acostumados a esses discursos.

Os alunos, curiosamente, 'demoraram' a perceber que esse discurso de segurança, a que faz alusão a propaganda, estaria apartado de acidentes de trânsito e que o léxico resgate não estaria, assim, associado a um resgate de uma equipe socorrista que ampara alguém que se fere no trânsito, que se perde em uma mata ou que cai em um buraco durante um período intenso de neve (notícias na Alemanha em que há um uso mais recorrente do 
vocábulo resgate). Como vimos, essa explicitação referencial precisou ser realizada pela professora no turno 51: "Então... quando eles falam PAGAMENTO do resgate... eles se referem a condição de sequestro ... SE-QUESTRO... sabem o que é sequestro?”.

O que acabamos de discutir são indícios de que a referenciação é um fato social (MONDADA; DUBOIS, 2003, p. 19) e que o léxico "não é um aparato para dizer o mundo como se estivesse ali discretizado e etiquetado" já que estamos considerando "uma perspectiva sociocognitiva, que não postula nem uma relação natural nem convencional, mas uma relação instável, social, histórica e negociada entre linguagem e mundo: relação como ação" (MARCUSCHI, 2004, p. 265).

Detectamos ainda que, nas partes 1 e 2, os sujeitos dialogam para demonstrar o olhar a respeito das práticas "comprar um carro blindado" em vez de "pagar resgate." Se considerarmos os elementos léxico-gramaticais, lemos uma interação em que os alunos tiveram dúvidas de vocabulário, o que, também, nos revelam sobre aspectos da língua de herança com que normalmente não têm (tanto) contato em casa, revelando traços de que "conhecer é uma atividade sociocognitiva e uma construção produzida na atividade intersubjetiva e recorrente" (MARCUSCHI, 2004, p. 269).

A professora Marta foi surpreendida pelo rumo das discussões, durante a efetivação da aula planejada em questão, o que se pôde linguisticamente observar nos alongamentos de vogais que realiza e em outras marcas do planejamento de sua fala como algumas hesitações.

A leitura que fazemos dos dados evidencia como conhecimentos (inter)culturais dos sujeitos professor e alunos explicam o modo como esses leem a propaganda/objeto de ensino da aula e como essa leitura dos alunos é diferente da esperada pela professora a partir da referência do vocábulo resgate e que a negociação da/na referenciação na aula é que garantiu a discretização (MARCUSCHI, 2004), afinal:

[...] as categorias não podem ser tomadas como estruturas invariantes capazes de realisticamente agruparem a realidade extra-mente de modo culturalmente insensível, sem uma nítida inserção sócio-cultural e histórica. Categorias não são entidades naturais e realistas. (MARCUSCHI, 2004, p. 276) 
[...] categorizar é uma maneira de pensar simbolicamente e não de nomear coisas, fatos, dados e assim por diante. (MARCUSCHI, 2004, p. 276)

[...] já que as categorias são discursivamente construídas, elas se dão tipicamente como objetos de discurso e não como fenômenos do mundo ou referentes externos e pré-existentes. As categorias são objetos de discurso para atuar no mundo. (MARCUSCHI, 2004, p. 277)

As noções de território e pertencimento, que se relacionam a não só aceitação, mas adesão aos valores e práticas de uma dada língua, podem acionar o modo como os processos de referenciação e discretização do vocábulo resgate são realizados. As tentativas de interação na construção de sentidos, no diálogo com a professora, chamam atenção para o fato de que as territorialidades se constituem nas atitudes dos falantes, tornando-os aptos a negociar sentidos, construindo significados para o termo em alemão, e a experiência que gera a reflexão sobre as práticas na sociedade brasileira, na alemã e o contato entre elas e suas implicações.

Essa sensibilidade didática do professor na e para a escolha de exemplares de gêneros implica(ria) "tratar, de forma sistemática e interdisciplinar, além dos usos da língua e dos diferentes sistemas semióticos nos textos, os processos sociais e cognitivos envolvidos nesses usos" (MATENCIO, 2007, p. 440). As interlocuções tornaram-se efetivas no momento em que os sujeitos comentavam e comparavam as realidades dos países, relacionando-as às ações e aos elementos léxico-gramaticais. Por fim, a efetivação da língua de herança se deu como o lugar de questionamentos.

A prática didatizadora da propaganda se efetiva no reconhecimento do gênero quando o aluno Pirm, no turno 31, destaca: “eles querem que a gente compra esse carro...”. A didatização da professora mediou com elementos de entonação e desafio a dúvida com "é uma boa interpretação" ou posições que instigavam os alunos a resolverem a questão, comparando posições sobre como é o resgate ou a blindagem de um carro no Brasil e na Alemanha. A professora incentiva os alunos a compararem e usarem elementos léxicogramaticais na comparação. Nesse sentido, os alunos são provocados a responderem sobre 
os sentidos possíveis para os processos nomeados em alemão, quando a professora diz "eu responderia assim se tivesse vivido na Alemanha".

A discordância também é um fato instigante que permeia a interação alunos-professora na aula, quando as nuances interculturais aparecem na interpretação marcada com, por exemplo, nos dizeres da professora, “[...] então, isso acontece de fato no Brasil”.

As reflexões metalinguísticas evidenciam o contato com a gramática de cada língua e as práticas culturais descritas estão a todo o momento na reflexão sobre o gênero em análise, ao comentar os elementos que descrevem o produto anunciado. As formas de contato entre os dois idiomas sinalizam muito mais as vivências entre os interlocutores na aula, do que os próprios elementos da gramática. Tais indícios sinalizam mais para a importância da rede de contato entre os alunos que, por vezes, a atividade de tradução, uma vez que expressões como guincho, blindagem e resgate indiciam um contato de repertório para além do corriqueiro.

As formas de pertencimento são uma maneira de acionar conhecimentos de uma cultura para fazer com que os alunos interpretem e produzam sentidos nas vivências em questão.

\section{Considerações Finais}

A observação aos trechos de aula, as memórias das vivências em campo, bem como os conhecimentos compartilhados entre os professora e alunos permitem que percebamos a intrincada rede de relações que permeiam a aula, o conhecimento sobre o idioma de herança, os mecanismos que fazem com que a gramática de uma língua faça emergir o conhecimento léxico-gramatical em outra, tornando o exercício de ensino-aprendizagem mais efetivo. Vimos que vários mecanismos e estratégias fazem com que uma aula de português como língua de herança "funcione" no contato com o grupo.

De fato, são as ações conduzidas e os conhecimentos que fundamentam o lidar com o outro e com outra língua, ainda que se produzam por meio dela relações de afetividade (como é o caso da língua de herança). 
Por fim, tomamos as relações como de fato importantes para fazer emergir relações que evocam pertencimento, fazendo com que o aluno se reconheça no intrincado território simbólico de regras que se produzem entre as fronteiras dos idiomas brasileiro e alemão. Faz sentido, assim, compartilhar relações para além da produção de regras de uma gramática. Nessa direção, faz ainda mais sentido tomar os gêneros como objeto de ensino, pois são eles que, para além de rememorar o conjunto de elementos linguísticos, retomam as práticas que ajudam a produzir sentido na prática social.

A cena demonstra a força de que exemplares de gêneros compreendidos como essas práticas socioculturais autênticas sejam a entrada mais produtiva para o trabalho de didatização de uma gramática enquadrada em uma abordagem contextualizada, de perceber as relações do falante de língua de herança com a própria língua e as práticas e dizeres de pertencimento, o que carrega marcas sobre relações com mãe, pai ou com quem lhe trouxe as primeiras experiências de contato com o português.

Ao efetivar a aula, circunstâncias e especificidades do contexto ensino-aprendizagem emergiram, dando-nos a oportunidade de organizar interculturalmente os nossos achados neste artigo e, assim, entendermos o perigo da/na generalização de um princípio já muito consolidado em língua materna ser simplesmente transposto para o de língua de herança: o trabalho com a gramática contextualizada em exemplares de gêneros.

$\mathrm{Na}$ e para a aula de português como língua de herança, há que se considerar concomitantemente, e de modo mais explícito, estereótipos, pré-construídos e discursos de/sobre o Brasil que estão a circular nos textos-objetos de ensino e, no caso deste trabalho, também de/sobre a Alemanha que emergem, na interação didática, (ex)postos na troca entre professora e alunos, por meio das categorias que vão sendo discursivamente construídas. Isso porque como se lida com a diferença é algo muito central em debates sobre interculturalidade.

Exemplos de processos de referenciação, como o que aqui apresentamos, realizados por falantes de português como língua de herança e monitorados pela professora falante de português como língua materna (com 35 anos de vida no Brasil e 6 anos na Alemanha) incitam perguntas como: - mas o que significa mesmo ser interculturalmente competente 
em termos linguísticos para um falante de PLH? De que modo essa competência estaria relacionada a habilidades interculturais? E uma faceta dessas habilidades poderiam ser vinculadas a compreensão do falante de LH de cada língua/cultura com que ele (con)vive? Essas línguas-culturas estariam a oferecer para esses falantes diferentes pontos de vista sobre o mundo? Afinal, como programações coletivas da mente (Woodside, 2010) culturas demarcam e, ao mesmo tempo, ampliam nossos territórios linguístico-identitários de pertencimento.

\title{
SCENES FROM A READING CLASS IN A PORTUGUESE TEACHING-LEARNING SETTING AS A HERITAGE LANGUAGE: INTERCULTURAL NOTES
}

\begin{abstract}
In this article, we present two scenes from a Portuguese class as a heritage language in Germany and demonstrate how the concepts of culture(s) as well as collective programming of the mind (Woodside, 2010) and territory(ies) are useful to understand why a Brazilian teacher is surprised by the way her Germanic-Brazilian students, born and raised in Germany, interpret the teaching text-object (a printed verb-visual advertisement). The intercultural notes we make help us to access and understand circumstances that account for the work with samples of texts in the heritage language education setting, which, in turn, point to the specificities of the teacher's job, who already teaches or wants to teach in that setting.
\end{abstract}

KEYWORDS: Culture, Heritage language; Text as a teaching object; Teacher work.

\section{REFERÊNCIAS}

ANDRADE, Mariana Kuntz. Autenticidade de materiais e ensino de línguas estrangeiras. Pandaemonium Germanicum, v. 20, n. 31, p. 1-29, 2017.

BRONCKART, Jean Paul; MACHADO, Anna Rachel. Procedimentos de análise de texto sobre o trabalho educacional. In: MACHADO, Anna Rachel (Org.). O ensino como trabalho: uma abordagem discursiva. Londrina: EDUEL, 2004, p. 131-163.

CASTELLOTTI, V. \& MOORE, D. Social Representations of Languages and Teaching. Guide for the Development of Language Education Policies in Europe From Linguistic Diversity to Plurilingual Education. Strasbourg, Council of Europe, 2002. http://www.coe.int/t/dg4/linguistic/source/castellottimooreen.pdf

CELANI, Maria Antonieta Alba. A Relevância da Lingüística Aplicada na Formação de uma Política Educacional Brasileira. In: FORTKAMP, M.B.M.; TOMITCH, L.M.B. (Orgs.) Aspectos da lingüistica aplicada. Florianópolis: Insular, 2000. 
DURANTI, Alessandro. Theories of culture. In: DURANTI, Alessandro. The Anthropology of Intentions Language in a World of Others, Cambridge (U.K.): University Printing House, 2015, p. 23- 50.

DUBOIS, D.; MONDADA, L. Construção dos objetos de discurso e categorização: uma abordagem dos processos de referenciação. In: CAVALCANTE, Mônica Magalhães; RODRIGUES, Bernadete Biasi; CIULLA, Alena (Orgs.). Referenciação. São Paulo: Contexto, 2003.

ERICKSON, Frederick. What makes school ethnography "ethnographic"? In: Council on Anthropology and Education Newsletter/Antropology \& Education Quarterly, v. 4 (2). Boston: Little Brown, 1973. p. 10-19

FLORES, Cristina; BARBOSA, Pilar. Clíticos no português de herança de emigrantes bilingues de segunda geração. Textos Seleccionados, XXVI Encontro da Associação Portuguesa de Linguistica, p. 81-98, 2011.

GUARDADO, Martin. Discourse, Ideology and Heritage Language Socialization. Micro and Macro Perspectives. Boston; Berlin: De Gruyter Mouton. Series: Contributions to the Sociology of Language. Volume 104, 2018.

GEERTZ, Clifford. 1973. The Interpretation of Cultures. New York: Basic Books.

HANCOCK, Black Hawk. Embodiment. A dispositional Approach to Racial and Cultural Analysis. In: JEROLMACK, Colin; KHAN, Shamus (Ed). Approaches to Etnography. Analysis and Representation in Participant Observation. New York, Oxford University Press, 2018, p.155-183.

HAESBAERT, Rogério. O mito da desterritorialização: Do "fim dos territórios" à multiterritorialidade. Rio de Janeiro: Bertrand Brasil, 2004.

MACHADO, A. R. (Org.). O ensino como trabalho: uma abordagem discursiva. Londrina, PR: Eduel, 2004.

MARCUSCHI, Luiz Antônio. O léxico: lista, rede ou cognição? In: NEGRI, Lígia; FOLTRAN, Maria José; OLIVEIRA, Roberta Pires de (Org.). Sentido e significação: em torno da obra de Rodolfo Ilari. São Paulo: Contexto, 2004.

MATENCIO, Maria de Lourdes. (2006). Formação do professor e representações sociais de língua(gem): por uma lingüística implicada. Filologia e Linguística Portuguesa, (8), 2006, p. 439-449. http://www.revistas.usp.br/flp/article/view/59765/62874

MODL, Fernanda de Castro; LEURQUIN, Eulália Vera Lúcia Fraga. Lusofonia em seus contextos de ensino, aprendizagem e formação de professores. Fólio - Revista de Letras, Vitória da Conquista, v.10, n.1, jan-jun de 2018, p. 333-340. 
MODL, Fernanda de Castro; BIAVATI, Nádia Dolores Fernandes. CULTURA ESCOLAR E DESNATURALIZAÇÃO DO OLHAR. Fólio - Revista de Letras, Vitória da Conquista, v. 8, n. 2, fev. 2018. ISSN 2176-4182. Disponível em: http://periodicos2.uesb.br/index.php/folio/article/view/2767

MODL, Fernanda de Castro. Rules of Behavior and Interaction in German and Brazilian Classrooms: (Inter)Cultural Uses of the Word in Schools. 1a. ed. Frankfurt am Main: Peter Lang, 2017. v. 1, 184 p.

MODL, Fernanda de Castro; LEURQUIN, Eulália. LUSOFONIA EM SEUS DIVERSOS CONTEXTOS DE ENSINO, APRENDIZAGEM E FORMAÇÃO DE PROFESSORES. Fólio - Revista de Letras, Vitória da Conquista, v. 10, n. 1, ago. 2018. ISSN 21764182. Disponível em: < http://periodicos2.uesb.br/index.php/folio/article/view/4169

MOITA LOPES, L. P. (Org.) Por uma Lingüística Aplicada Indisciplinar. São Paulo: Parábola Editorial, 2006.

MYERS, Michael D; AVISON, David E. An Introduction to Qualitative Research. In: Information Systems Qualitative Research in Information Systems: A Reader. MYERS, Michael D; AVISON, David E (orgs), SAGE Publications, London, 2002. ProQuest Ebook Central, p. 1-12.

OCHS, Elionor. Transcription as Theory. In: OCHS, Elionor; SCHIEFFELIN. Development Pragmatics. New York: Academic Press, 1979, p. 4-72.

PINTO, A. P. Gêneros discursivos e ensino de língua inglesa. In: A. P. Dionísio; A. R. Machado e M. A. Bezerra (orgs.): Gêneros textuais \& Ensino. Rio de Janeiro: Lucerna, p. $47-$ 57. 2002.

PONTARA, Claudia Lopes; CRISTOVÃO, Vera Lucia Lopes. Gramática/análise linguística no ensino de inglês (língua estrangeira) por meio de sequência didática: uma análise parcial. DELTA: Documentação e Estudos em Linguística Teórica e Aplicada, v. 33, n. 3, 2017, p. 873-909.

POSSENTI, Sírio. Por que (não) ensinar gramática na escola. Campinas; São Paulo: ALB; Mercado de Letras, 1996.

QUINN, Naomi (Ed). Finding Culture in Talk: a collection of methods. Palgrave Macmillan, England, 2005.

SERRRANI, S. (Org.). Discurso e cultura na aula de lingua: currículo, leitura, escrita. Campinas: Pontes, 2005

STÜRMER, Arthur Breno; DA COSTA, Benhur Pinós. Território: aproximações a um conceito-chave da geografia, Geografia, Ensino \& Pesquisa, Vol. 21 (2017), n.3, p. 5060ISSN: 2236-4994 DOI: 10.5902/2236499426693. Disponível em: https://periodicos.ufsm.br/geografia/article/viewFile/26693/pdf. 
WOODSIDE, Arch G. Case Study Research: Theory, Methods, Practice. Esmerald Group Publishing Limited, Bingley, United Kingdom, 2010, 440p.

ZANDWAIS, Ana. Demandas da pesquisa e diálogos entre teoria e prática. In: LEFFA, Vilson; ERNST, Aracy (Org.). Linguagens: metodologias de ensino e pesquisa. Pelotas: Educat, 2012. p. 13-26.

Recebido em: 30/05/2020.

Aprovado em: 29/06/2020. 